Article

\title{
Hierarchically Assembled Plasmonic Metal-Dielectric-Metal Hybrid Nano-Architectures for High-Sensitivity SERS Detection
}

\author{
Puran Pandey ${ }^{1}\left(\mathbb{D}\right.$, Min-Kyu Seo $^{1}$, Ki Hoon Shin $^{1}$, Young-Woo Lee ${ }^{2, * \mathbb{D}}$ and Jung Inn Sohn ${ }^{1, *}$ \\ 1 Division of Physics and Semiconductor Science, Dongguk University-Seoul, Seoul 04620, Korea; \\ ppcpurans@gmail.com (P.P.); seominkyuu@gmail.com (M.-K.S.); kihoonshin@dongguk.edu (K.H.S.) \\ 2 Department of Energy Systems, Soonchunhyang University, Asan-si 31538, Korea \\ * Correspondence: ywlee@sch.ac.kr (Y.-W.L.); junginn.sohn@dongguk.edu (J.I.S.)
}

Citation: Pandey, P.; Seo, M.-K.; Shin, K.H.; Lee, Y.-W.; Sohn, J.I.

Hierarchically Assembled Plasmonic Metal-Dielectric-Metal Hybrid Nano-

Architectures for High-Sensitivity

SERS Detection. Nanomaterials 2022, 12, 401. https://doi.org/10.3390/ nano12030401

Academic Editor: Onofrio M. Maragò

Received: 4 January 2022

Accepted: 24 January 2022

Published: 26 January 2022

Publisher's Note: MDPI stays neutral with regard to jurisdictional claims in published maps and institutional affiliations.

Copyright: () 2022 by the authors. Licensee MDPI, Basel, Switzerland. This article is an open access article distributed under the terms and conditions of the Creative Commons Attribution (CC BY) license (https:// creativecommons.org/licenses/by/ $4.0 /)$.

\begin{abstract}
In this work, we designed and prepared a hierarchically assembled 3D plasmonic metaldielectric-metal (PMDM) hybrid nano-architecture for high-performance surface-enhanced Raman scattering (SERS) sensing. The fabrication of the PMDM hybrid nanostructure was achieved by the thermal evaporation of $\mathrm{Au}$ film followed by thermal dewetting and the atomic layer deposition (ALD) of the $\mathrm{Al}_{2} \mathrm{O}_{3}$ dielectric layer, which is crucial for creating numerous nanogaps between the core Au and the out-layered Au nanoparticles (NPs). The PMDM hybrid nanostructures exhibited strong SERS signals originating from highly enhanced electromagnetic (EM) hot spots at the $3 \mathrm{~nm}$ $\mathrm{Al}_{2} \mathrm{O}_{3}$ layer serving as the nanogap spacer, as confirmed by the finite-difference time-domain (FDTD) simulation. The PMDM SERS substrate achieved an outstanding SERS performance, including a high sensitivity (enhancement factor, EF of $1.3 \times 10^{8}$ and low detection limit $10^{-11} \mathrm{M}$ ) and excellent reproducibility (relative standard deviation $(\mathrm{RSD})<7.5 \%$ ) for rhodamine $6 \mathrm{G}(\mathrm{R} 6 \mathrm{G})$. This study opens a promising route for constructing multilayered plasmonic structures with abundant EM hotspots for the highly sensitive, rapid, and reproducible detection of biomolecules.
\end{abstract}

Keywords: SERS; metal-dielectric-metal; Au nanoparticles; hot spots; FDTD simulation

\section{Introduction}

Owing to its extremely high sensitivity, ability to work in real time, and multiplexing detection capability, surface-enhanced Raman scattering (SERS) has emerged as a powerful detection technique for sensing molecules through its unique fingerprint vibrational spectrum [1-5]. It has tremendous potential for single-molecule level detection [6,7], the investigation of live cells [8,9], the monitoring of catalytic reactions [10,11], and sensing molecules, in both liquid and solid samples [12,13]. In SERS, the Raman signals of analytes can be amplified by several orders of magnitude $\left(10^{8}-10^{10}\right)$ based on two mechanisms: electromagnetic mechanism (enhancement of $\sim 10^{6}-10^{8}$ ) and chemical mechanism (enhancement of $\sim 10^{2}-10^{4}$ ) [14-16]. The SERS enhancement mostly relies on the amplification of the electromagnetic field-i.e., electromagnetic (EM) hot spots generated by the excitation of the localized surface plasmon resonance (LSPR) of the metal nanostructures [17]. Therefore, plasmonic metallic nanostructures including $\mathrm{Au}, \mathrm{Ag}$, and $\mathrm{Cu}$ have been fabricated to prepare an excellent SERS substrate for sensing molecules [18-20]. Designing and optimizing the geometry of a plasmonic nanostructure, such as its size [21], sharp corners [22], tips [23], surface roughness [24], and interparticle gaps [25], is essential in order to provide a strong EM hotspot and hence enhance SERS signal intensities. Among these, the interparticle gap structure has attracted considerable attention thanks to its ability to provide extremely strong EM hot spots within a sub-nanometer gap [26]. The precise control of nanogaps between plasmonic nanoparticles (NPs) at a nanometer scale is crucial to produce a high density of strong and stable EM hot spots. To maintain the specific sub-nanometer gap, 
a dielectric layer can be considered as a nanogap spacer between two layered plasmonic metal nanostructures-namely, metal-dielectric-metal hybrid nano-architectures [27-30]. The dielectric spacer offers several benefits: protecting the plasmonic core from oxidation, tunning the LSPR properties, and maintaining a sub-nanometer gap between metal nanostructures to obtain a strong EM hotspot [31-34]. Therefore, it is of great significance to construct a unique 3D nano-architecture SERS substrate that comprises a hierarchical assembly of plasmonic NPs, separated by a dielectric spacer, for achieving an extremely high SERS activity.

Inspired by the above discussion, we report a facile method for fabricating abundant nanogaps containing hierarchically assembled 3D plasmonic metal-dielectric-metal (PMDM) hybrid nano-architectures for superior SERS detection in this work. However, the developed PMDM hybrid SERS sensor is considerably different from the above-mentioned metal-dielectric-metal structure in terms of the preparation method and architecture of the SERS platform. The PMDM hybrid nanostructures were prepared by the thermal evaporation of $\mathrm{Au}$ film followed by the thermal annealing and atomic layer deposition (ALD) of the $\mathrm{Al}_{2} \mathrm{O}_{3}$ dielectric layer. We achieved an enormous SERS enhancement of the PMDM hybrid nanostructures, with a maximum enhancement factor $(\mathrm{EF})$ of $1.3 \times 10^{8}$ and a low detection limit of $10^{-11} \mathrm{M}$ R6G molecules. We further observed the excellent reproducibility of the SERS substrate with relative standard deviation (RSD) values of less than $7.5 \%$. To support the experimental SERS performance, we conducted the finite-difference time-domain (FDTD) simulation of hybrid nanostructures and showed that a high density of strong EM hot spots was produced between the Au core and numerous out-layered $\mathrm{Au}$ NPs at the $\mathrm{Al}_{2} \mathrm{O}_{3}$ nanogap regions.

\section{Materials and Methods}

\subsection{Hybrid Nanostructures Fabrication}

$\mathrm{SiO}_{2} / \mathrm{Si}$ substrates (purchased from Sehyoung wafertech, Seoul, Korea) were cleaned by acetone, isopropyl alcohol (Sigma-Aldrich, Saint Louis, MO, USA), and deionized water for $10 \mathrm{mins}$ in sequence in an ultrasonic cleaner and dried at room temperature. $\mathrm{Au}$ films $(10 \mathrm{~nm})$ were deposited on $\mathrm{SiO}_{2} / \mathrm{Si}$ substrates using thermal evaporation, where the thickness of films was controlled by the deposition time. The $10 \mathrm{~nm}$ Au films was annealed in a rapid thermal annealing (RTA) chamber at $800{ }^{\circ} \mathrm{C}$ for $120 \mathrm{~s}$ for the fabrication of core $\mathrm{Au}$ NPs arrays based on the solid-state dewetting [35,36]. Subsequently, the ultrathin dielectric layer-i.e., $3 \mathrm{~nm} \mathrm{Al}_{2} \mathrm{O}_{3}$ film-was deposited on the as-prepared core $\mathrm{Au}$ NPs via the ALD method. Then, the $5 \mathrm{~nm} \mathrm{Au}$ films were deposited on the surface of $\mathrm{Au} / \mathrm{Al}_{2} \mathrm{O}_{3}$ nanostructures, followed by annealing at $450{ }^{\circ} \mathrm{C}$ for $120 \mathrm{~s}$ to produce highly dense smallsized $\mathrm{Au}$ NPs on the surface of $\mathrm{Au} / \mathrm{Al}_{2} \mathrm{O}_{3} \mathrm{NPs}$, which are referred to as a hierarchically assembled PMDM ( $\mathrm{Au} / \mathrm{Al}_{2} \mathrm{O}_{3} / \mathrm{Au}$ ) nanostructures. For comparison, double dewetting $\mathrm{Au}$ nanostructures were prepared by a similar method without using an $\mathrm{Al}_{2} \mathrm{O}_{3}$ spacer.

\subsection{Sample Characterization}

The morphological characterization and elemental analysis of the as-synthesized hybrid nanostructures fabricated on $\mathrm{SiO}_{2} / \mathrm{Si}$ substrates was performed using a field emission scanning electron microscope (FE-SEM, Hitachi S-7400, Tokyo, Japan), coupled with the energy-dispersive x-ray spectroscopy (EDS) analysis. Moreover, the crystalline information was examined by X-ray diffraction (XRD, Rigaku Ultima IV diffractometer, Tokyo, Japan) with $\mathrm{Cu}-\mathrm{K} \alpha$ radiation, whereas the chemical states were evaluated using $X$-ray photoelectron spectroscopy (XPS, Veresprobe II, Ulvac-phi, Chigasaki, Japan).

\subsection{SERS Analysis}

Rhodamine 6G (R6G, Sigma-Aldrich, Saint Louis, MO, USA) was used as a probe molecule to determine the SERS activity of the as-prepared PMDM hybrid nanostructures. For the preparation of the samples for SERS measurements, the SERS substrates were immersed in different concentrations of R6G solution ranging from $10^{-12}$ to $10^{-5} \mathrm{M}$ for 
$2 \mathrm{~h}$ to allow the sufficient adsorption of R6G molecules on plasmonic nanostructures. SERS measurements were performed using confocal Raman spectroscopy (HEDA, NOST, Seongnam, Korea) at room temperature. SERS signals were acquired using an incident laser with a wavelength of $532 \mathrm{~nm}$ with a power of $0.1 \mathrm{~mW}$ (laser spot size $\sim 1 \mu \mathrm{m}$ ), $100 \times$ objective lens (numerical aperture $=0.80$ ), and acquisition time of $10 \mathrm{~s}$. To determine the $\mathrm{EF}$, the Raman spectrum of $\mathrm{R} 6 \mathrm{G}\left(10^{-2} \mathrm{M}\right)$ adsorbed on the $\mathrm{SiO}_{2} / \mathrm{Si}$ substrates was evaluated as above.

\subsection{FDTD Simulation}

The EM field distribution was calculated with the FDTD method (Lumerical Solutions Inc., Vancouver, BC, Canada). In our simplified unit of the simulation model, the core Au $\mathrm{NP}$ was assumed to be a larger hemisphere coated with a dielectric spacer layer $(3 \mathrm{~nm}$ $\mathrm{Al}_{2} \mathrm{O}_{3}$ ) followed by the out-layered small Au NPs. The diameter of the core, top, and surrounding Au NPs was supposed to be 180, 60, and $30 \mathrm{~nm}$, respectively. Furthermore, the incident light source of a plane wave, surrounding medium (air), perfectly matched layer (PML) as an absorption boundary in z-boundary, periodic boundary condition for $\mathrm{x}$ and $\mathrm{y}$ directions, and mesh size $(1 \mathrm{~nm})$ were selected for the simulation to compute the EM field distribution. The near-field EM field intensity was calculated in the vicinity of the nanostructures using two monitors in $\mathrm{X}-\mathrm{Y}$ and $\mathrm{Y}-\mathrm{Z}$ directions. The data of a refractive index for $\mathrm{Au}$ were obtained from the Johnson and Christy model [37]. The data for $\mathrm{SiO}_{2}$ and $\mathrm{Al}_{2} \mathrm{O}_{3}$ were acquired from the model data provided by the software.

\section{Results and Discussion}

Figure 1a shows the fabrication procedures and surface morphology of the hierarchically assembled PMDM hybrid nanostructures fabricated on $\mathrm{Si} / \mathrm{SiO}_{2}$ substrate. The combination of double dewetting and the ALD approach was employed for the preparation of the SERS substrates. The aim of using this approach with a dielectric layer between $\mathrm{Au}$ NPs is to obtain hierarchical nano-architectures with a strong plasmonic response and massive gap-introduced EM hot spots. First, high-density core Au NPs arrays were prepared based on the thermal dewetting of $10 \mathrm{~nm}$ Au thin film at $800{ }^{\circ} \mathrm{C}$ for $120 \mathrm{~s}$. The average diameter $\mathrm{Au}$ NPs was found to be $\sim 136 \mathrm{~nm}$ and the corresponding size distribution is shown in the histogram of Figure S1. The surface morphology of the fabricated Au NPs on the substrate with well-dispersed semispherical or somewhat faceted NPs is shown in the SEM image of Figure 1b. Next, we deposited $5 \mathrm{~nm}$ Au films on as-prepared core Au NPs arrays and then annealed them at $450{ }^{\circ} \mathrm{C}$ for $120 \mathrm{~s}$. This repeated dewetting of Au films resulted in the formation of a very high density of Au NPs, as shown in Figure 1c. The larger core Au NPs were surrounded by comparatively small Au NPs. However, the spacing between them was too large, meaning they cannot be considered a good candidate for SERS substrates. Therefore, we deposited a $3 \mathrm{~nm} \mathrm{Al}_{2} \mathrm{O}_{3}$ thin film on core $\mathrm{Au}$ NPs to fabricate a metal-dielectric core-shell nanostructure via the ALD approach. Subsequently, a $5 \mathrm{~nm}$ Au thin film was deposited on the $\mathrm{Au} / \mathrm{Al}_{2} \mathrm{O}_{3}$ nanostructure followed by annealing at $450^{\circ} \mathrm{C}$ for $120 \mathrm{~s}$, which gives rise to the formation of hierarchically assembled PMDM hybrid nanostructures, as shown in Figure 1d. These hierarchical PMDM hybrid nanostructures provide not only an increased surface coverage and roughness, but also multiple out-layered small-sized Au NPs separated with a nanogap layer of dielectric $\mathrm{Al}_{2} \mathrm{O}_{3}$ from the core $\mathrm{Au}$ NPs. The out-layered Au NPs can be distinctly observed along the surface of core Au NPs in Figure 1d. Moreover, we confirmed the formation of PMDM hybrid nanostructures by using EDS mapping based on elemental analysis, as shown in Figure $1 \mathrm{e}-\mathrm{h}$. 
(a)
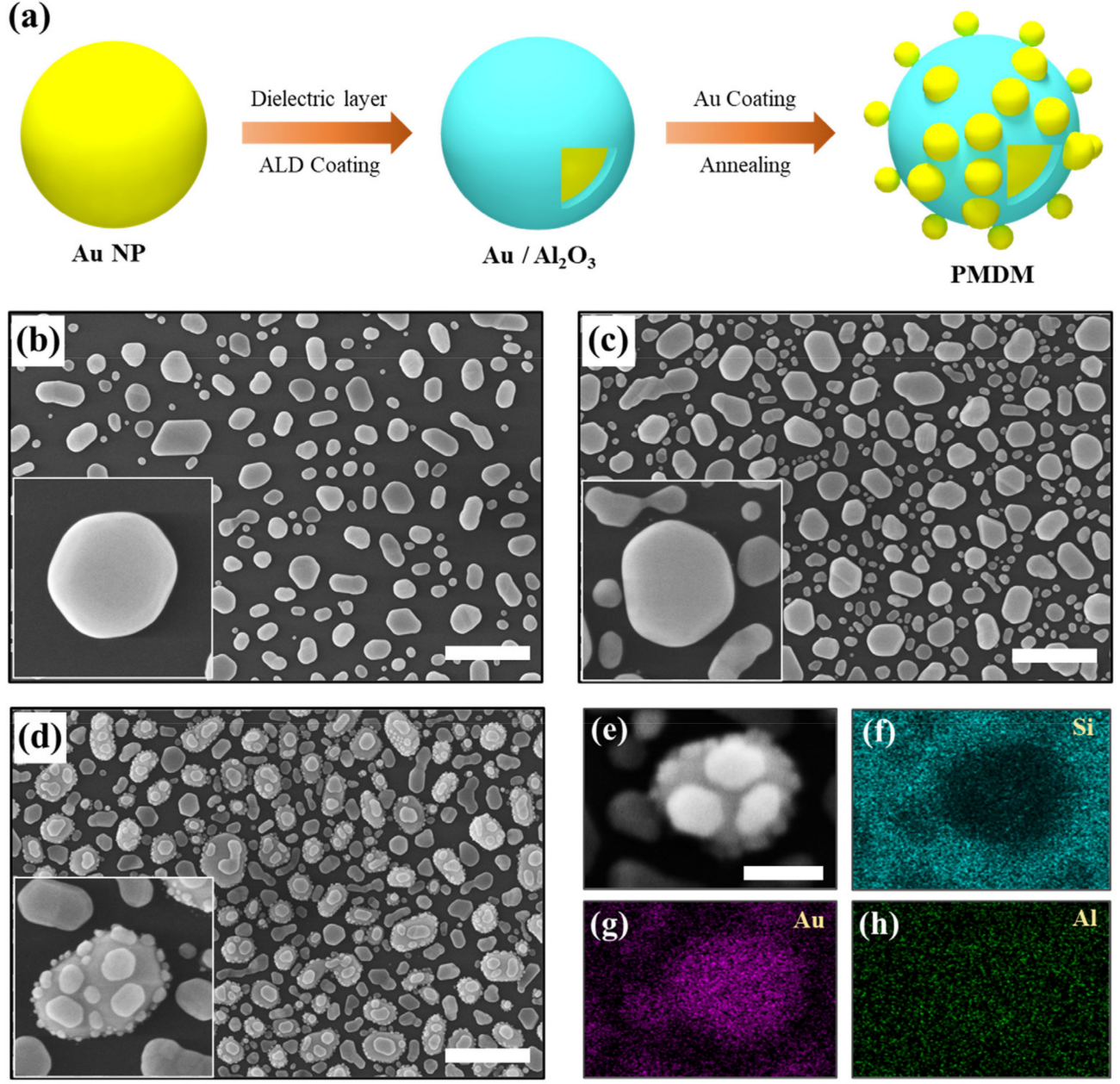

Figure 1. (a) Schematic illustration of the fabrication of hierarchically assembled plasmonic metaldielectric-metal (PMDM) nano-architectures. (b) SEM image of Au nanoparticles (NPs) fabricated on $\mathrm{Si} / \mathrm{SiO}_{2}$ substrate by the annealing of $\mathrm{Au}$ film $(10 \mathrm{~nm})$ at $800{ }^{\circ} \mathrm{C}$ for $120 \mathrm{~s}$. (c) Fabrication of double dewetting $\mathrm{Au}$ NPs arrays grown on $\mathrm{Au}$ NPs $(\mathrm{Au} / \mathrm{Au})$ by the deposition of $5 \mathrm{~nm}$ Au film and subsequent annealing at $450{ }^{\circ} \mathrm{C}$ for $120 \mathrm{~s}$. (d) SEM image of hierarchically assembled PMDM hybrid nano-architectures. Scale bar: $400 \mathrm{~nm}$. (e-h) EDS mapping of PMDM hybrid nanostructures grown on $\mathrm{Si} / \mathrm{SiO}_{2}$ substrate, where elemental maps are $\mathrm{Si}$ (blue), $\mathrm{Au}$ (red), and $\mathrm{Al}$ (green). Scale bar: $100 \mathrm{~nm}$.

The crystalline structures of the Au and hybrid nanostructures were examined with an XRD pattern, in which all samples possessed almost the same diffraction peaks as those shown in Figure 2a. Four distinct diffraction peaks were observed at 38.3, 44.3, 64.7, and $77.7^{\circ}$ corresponding to the (111), (200), (220), and (311) planes of the face-centered cubic phase of Au (JCPDS no. 04-784), revealing the formation of Au NPs. Furthermore, the XPS spectra of the Au and PMDM hybrid nanostructures were thoroughly analyzed to confirm the elemental and chemical states. Figure $2 b$ shows the XPS survey spectra of the $\mathrm{Au}$ NPs, double dewetted $\mathrm{Au} / \mathrm{Au}$ NPs, and PMDM hybrid nanostructures, discovering all the elements as expected. In particular, the $\mathrm{Au} 4 \mathrm{f}, \mathrm{Al} 2 \mathrm{p}, \mathrm{Au} 4 \mathrm{~d}$, and $\mathrm{O} 1$ s elements are all presented in the XPS survey spectra of PMDM hybrid nanostructures. As shown in the high-resolution XPS spectrum of Au $4 \mathrm{f}$ (Figure 2c), two characteristic peaks located at binding energies 84.2 and $87.9 \mathrm{eV}$ are attributed to $4 \mathrm{f}_{7 / 2}$ and $4 \mathrm{f}_{5 / 2}$, respectively, indicating the presence of a metallic state of $\mathrm{Au}$ [38]. In addition, the high-resolution XPS analysis (Figure 2d) depicts the peak at $74.1 \mathrm{eV}$ assigned to $\mathrm{Al} 2 \mathrm{p}$, originating from the $\mathrm{Al}_{2} \mathrm{O}_{3}$ film [39]. The above evidence reveals the existence of dielectric spacer $\mathrm{Al}_{2} \mathrm{O}_{3}$ in the PMDM hybrid nanostructures. 
(a)

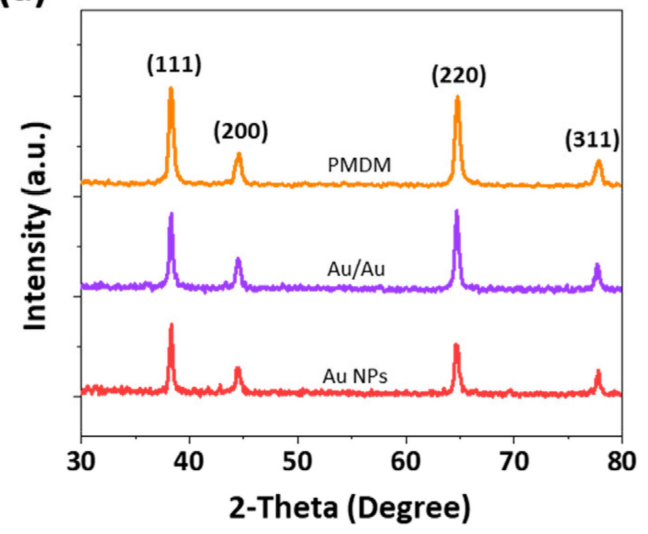

(c)

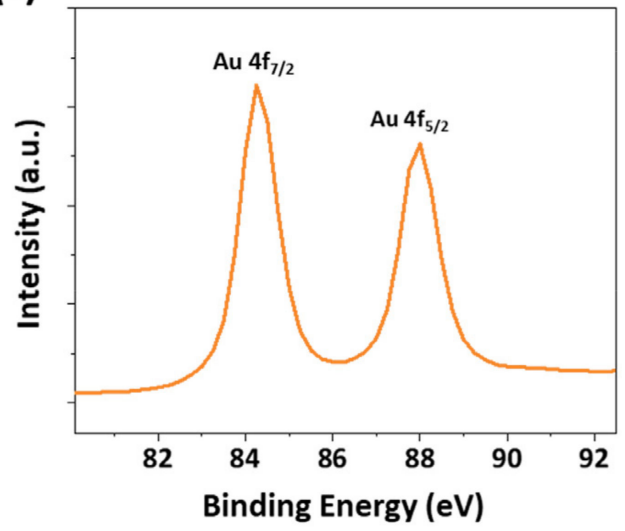

(b)

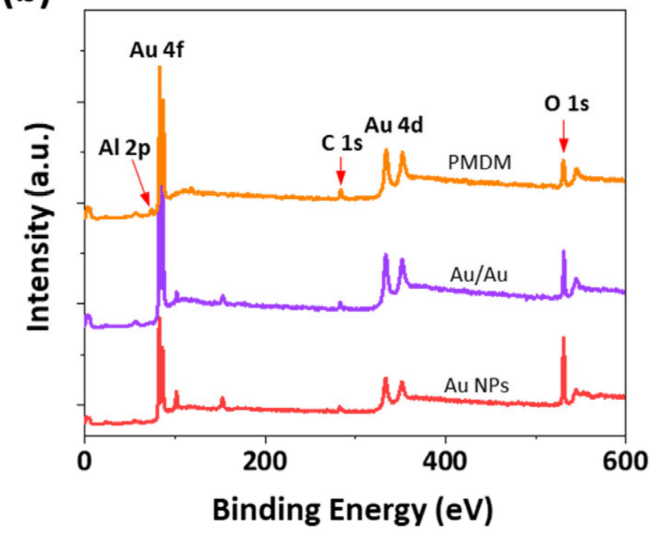

(d)

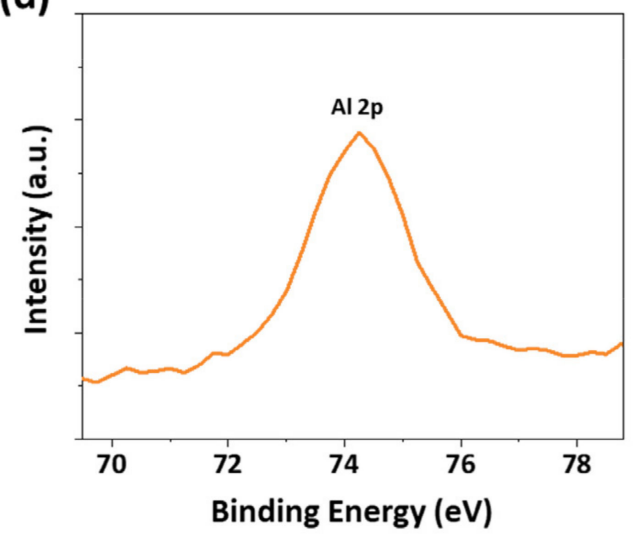

Figure 2. (a) XRD patterns of three different plasmonic nanostructures: $\mathrm{Au}, \mathrm{Au} / \mathrm{Au}$, and PMDM hybrid nanostructures, as labeled. (b) XPS survey spectra of Au, Au/Au, and PMDM hybrid nanostructures. (c,d) High-resolution XPS spectra of $\mathrm{Au} 4 \mathrm{f}$ and $\mathrm{Al} 2 \mathrm{p}$ of PMDM hybrid nanostructure.

Next, FDTD simulations were used to calculate the spatial distribution of the near-field EM field of the plasmonic Au and PMDM hybrid nanostructures deposited on $\mathrm{SiO}_{2} / \mathrm{Si}$ substrate. The FDTD simulation models were constructed by mimicking the real experimental results of nanostructures obtained from SEM images, as shown in Figure 3a,d. The FDTD simulation of EM field distribution modes for each nanostructure in the X-Y and X-Z directions was analyzed with an incident laser source with a $532 \mathrm{~nm}$ wavelength. As shown in Figure 3b,c, the Au NP provides a hot spot at the interface between the Au NPs and $\mathrm{SiO}_{2}$ substrate with a maximal EM field strength $\left(|\mathrm{E}| /\left|\mathrm{E}_{0}\right|\right)$ of 5.8. Figure 3e,f show the FDTD calculation of the localized EM field distribution in PMDM hybrid nanostructures with a $3 \mathrm{~nm} \mathrm{Al} \mathrm{O}_{3}$ nanogap. The high density of the strongest hot spots is induced at the dielectric $\mathrm{Al}_{2} \mathrm{O}_{3}$ nanogap between the core $\mathrm{Au}$ NPs and the out-layered $\mathrm{Au}$ NPs due to the plasmon coupling between the Au NPs. Compared with Au NPs, the EM field strength was much higher for the PMDM hybrid nanostructures-i.e., $|\mathrm{E}| /\left|\mathrm{E}_{0}\right| \approx 21.5$. It is widely known that the SERS EF can be theoretically predicted from the local EM field enhancement $\left(|\mathrm{E}| /\left|\mathrm{E}_{0}\right|\right)$ of nanostructures-i.e., SERS EF is proportional to the fourth power of $|\mathrm{E}| /\left|\mathrm{E}_{0}\right|$ [40-42]. Based on the above relation, the theoretical SERS EF is estimated to be $\sim 2.14 \times 10^{5}$ for hybrid nanostructures, which is two orders higher than Au NPs. These results suggest that a high density of strong EM hotspots can be highly beneficial for SERS enhancement. It should be noted that the theoretical calculation of SERS EF from the EM enhancement is usually 2-3 orders lower than the experimental results due to the exclusion of chemical enhancement. 
(a)

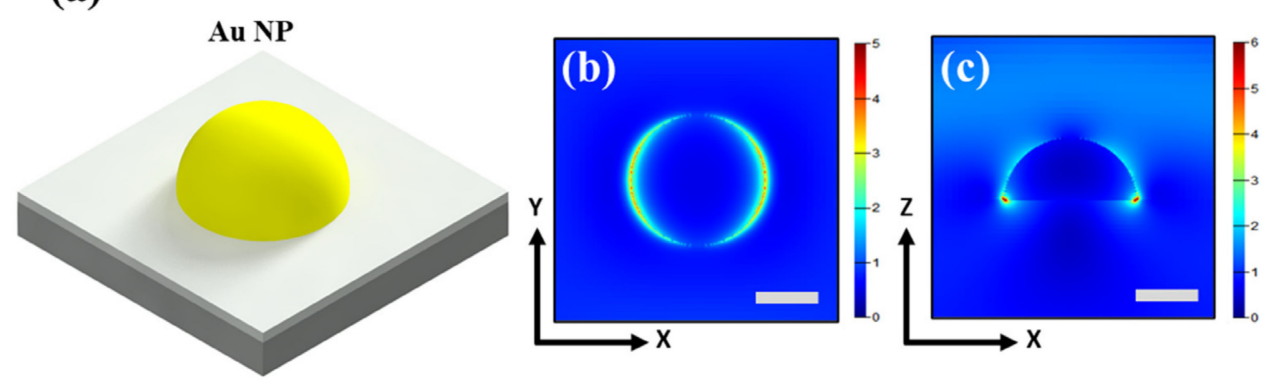

(d)

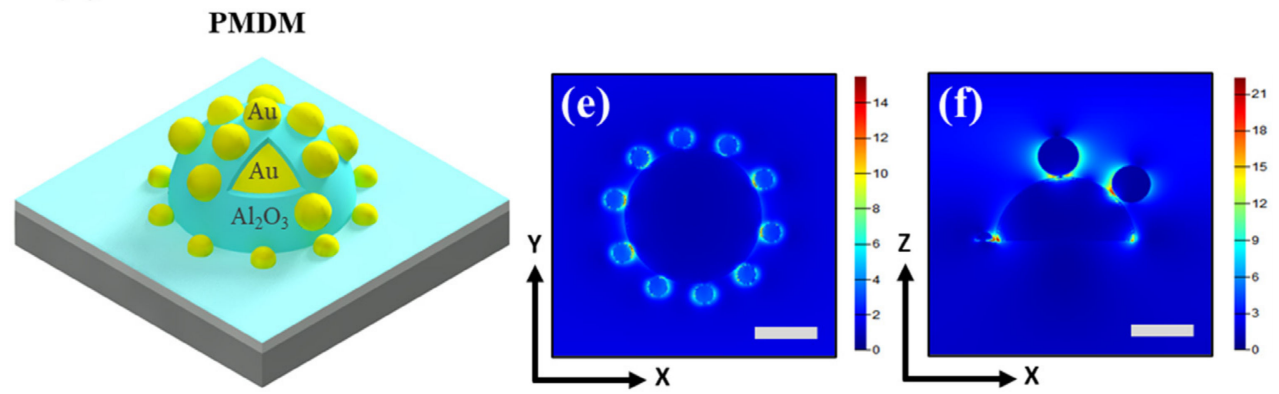

Figure 3. Finite-difference time-domain (FDTD) simulation of EM field distribution of plasmonic nanostructures under the radiation of a $532 \mathrm{~nm}$ laser. (a) Simulation model and EM field distribution of Au NP at (b) X-Y and (c) X-Z view. (d) Simulation model of PMDM hybrid nanostructure and corresponding EM field distribution in (e) X-Y and (f) X-Z views. Scale bar: $100 \mathrm{~nm}$.

Figure 4 shows the SERS performance of PMDM hybrid nanostructures using R6G as a probe molecule and an excitation laser of wavelength $532 \mathrm{~nm}$. The comparison of the SERS performance of different SERS-active substrates with a $10^{-6} \mathrm{M}$ R6G concentration is demonstrated in Figure 4a, and the corresponding SERS enhancement is summarized in terms of Raman peak intensity in Figure 4b. Several of the most prominent Raman peaks of R6G are observed at the wavenumbers of 612, 776, 1185, 1310, 1363, 1506, 1574, and $1650 \mathrm{~cm}^{-1}$, which are consistent with the characteristic peaks of R6G reported in the literature $[43,44]$. The band assignment of all the Raman peaks of R6G is also summarized in Table S1. In particular, the Raman peak intensity of the PMDM hybrid nanostructures at the wavenumber of $1650 \mathrm{~cm}^{-1}$ is about 3.3 and 2.2 times higher compared to that of the $\mathrm{Au}$ NPs and $\mathrm{Au} / \mathrm{Au}$ NPs. As confirmed by the FDTD simulation results, it is obvious that the PMDM hybrid nanostructures exhibit the best performance due to the strong EM field enhancement. It is observed that the intensity of the R6G Raman signal on the hybrid nanostructure is much enhanced, as compared to that of Au NPs. Therefore, the PMDM hybrid nanostructures-based SERS substrates was further analyzed to identify the detection limit, enhancement factor, and reproducibility. Figure 4c,d show the SERS spectra of different concentrations of R6G molecules adsorbed on hybrid nanostructures in the range of $10^{-5}$ to $10^{-12} \mathrm{M}$. The Raman intensity is gradually reduced with the decreased R6G concentration. The lowest detectable concentration reaches $10^{-11} \mathrm{M}$, where certain Raman peaks such as 1363 and $1650 \mathrm{~cm}^{-1}$ can be identified, indicating that the SERS substrate possesses a high SERS sensitivity. To quantitatively study the SERS performance of hybrid nanostructures, the SERS EF was calculated using the relation EF $=\left(I_{S E R S} / C_{S E R S}\right) /\left(I_{R} / C_{R}\right)$, where $I_{S E R S}$ and $I_{R}$ correspond to the Raman peak intensities of R6G obtained from the SERS substrate and reference $\left(\mathrm{SiO}_{2}\right)$ substrate, whereas $C_{S E R S}$ and $C_{R}$ represent the concentrations of R6G molecules on SERS substrate and reference substrate, respectively. The minimum detectable limit for the SERS substrate was $10^{-11} \mathrm{M}$, whereas the lowest detection for reference substrate was $10^{-2} \mathrm{M}$. Therefore, the SERS EF of PMDM hybrid nanostructures for Raman peak $1650 \mathrm{~cm}^{-1}$ was estimated as $1.3 \times 10^{8}$, which was much higher than that of 
the other SERS substrates reported in the literature (Table S2). Furthermore, we tested the reproducibility of the as-prepared SERS substrate by conducting the SERS measurement in several locations. The color contour plot of the SERS spectra of $10^{-6} \mathrm{M}$ R6G measured at random 30 different locations is presented in Figure 4e and the corresponding SERS spectra are presented in Figure S2. The contour plot demonstrates the similar color of Raman signals, signifying the comparable intensity of the Raman signals due to the homogeneous distribution of EM hot spots. In addition, the SERS mapping was performed in an area of $10 \mu \mathrm{m} \times 10 \mu \mathrm{m}$ to further confirm the reproducibility. The RSD values corresponding to Raman peaks 776 and $1363 \mathrm{~cm}^{-1}$ were calculated to be $6.8 \%$ and $7.4 \%$, respectively, indicating the good reproducibility of SERS substrates.

(a)

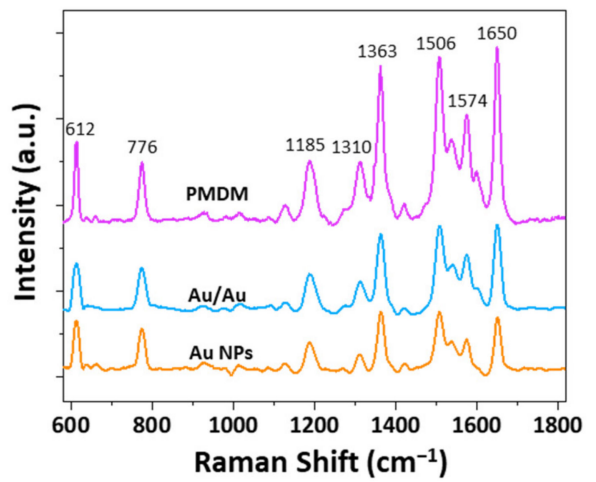

(d)

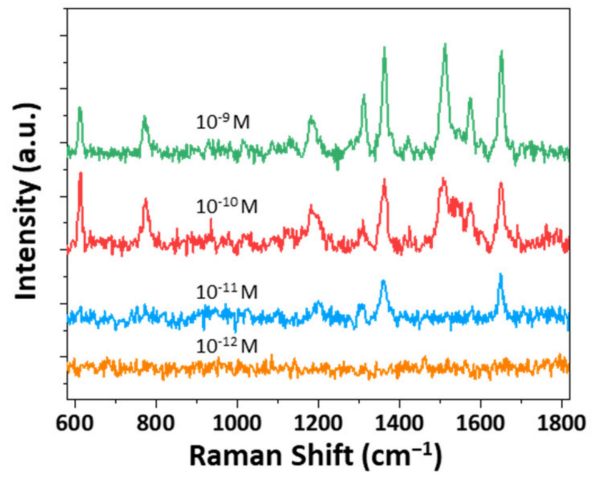

(b)

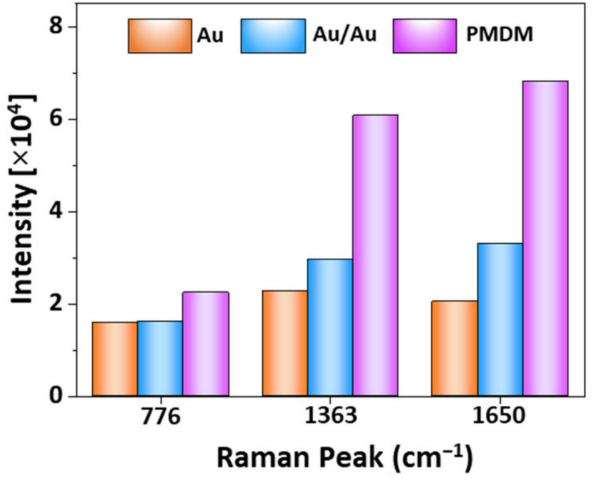

(e)

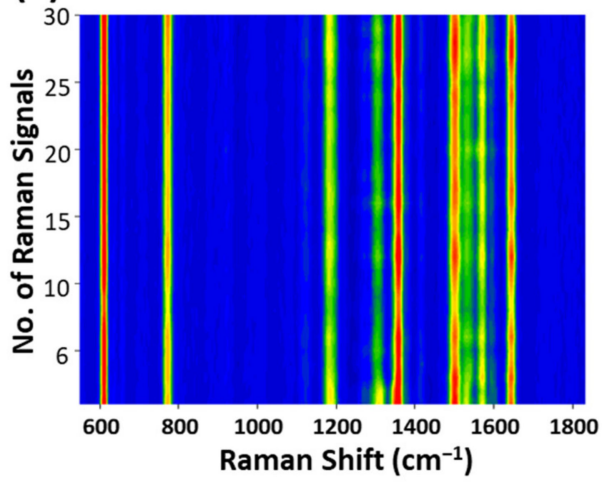

(c)

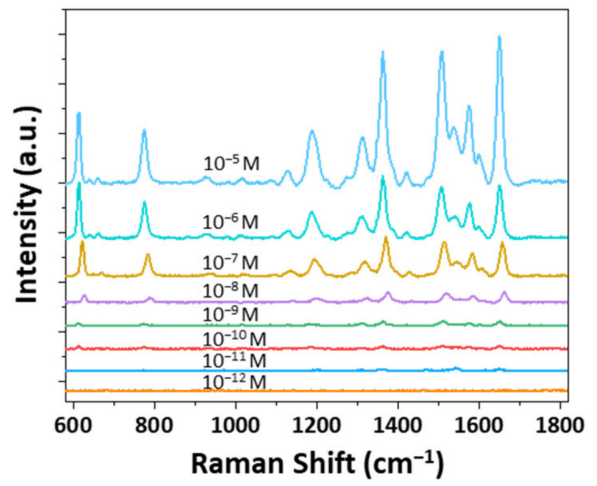

(f)

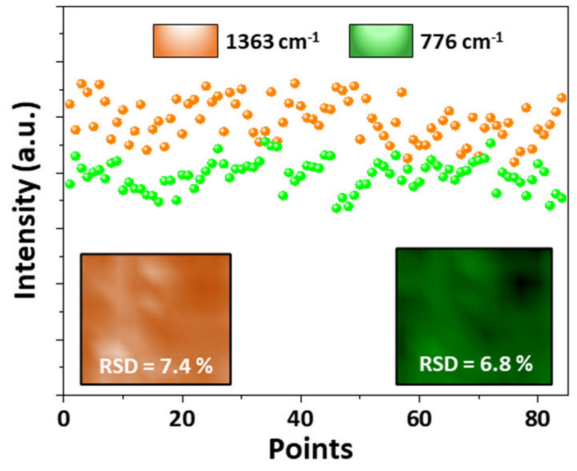

Figure 4. (a) Comparison of the SERS spectra of R6G molecules $\left(10^{-6} \mathrm{M}\right)$ on $\mathrm{Au}, \mathrm{Au} / \mathrm{Au}$, and PMDM hybrid nanostructure-based SERS substrates. (b) Corresponding plot of intensity at Raman peaks of 776,1363 , and $1650 \mathrm{~cm}^{-1}$. (c) SERS spectra of R6G molecules on PMDM hybrid nanostructure-based SERS substrate with different concentrations ranging from $10^{-5}$ to $10^{-12} \mathrm{M}$. (d) Magnified SERS spectra of R6G with low concentrations showing the distinct Raman peaks. SERS uniformity and reproducibility of the PMDM hybrid nanostructure substrate. (e) SERS contour maps of 30 spots and (f) plot of Raman intensities of 776 and $1363 \mathrm{~cm}^{-1}$ randomly selected from SERS mapping in an area of $10 \mu \mathrm{m} \times 10 \mu \mathrm{m}$. (Insets) SERS intensity mapping of 776 and $1363 \mathrm{~cm}^{-1}$.

\section{Conclusions}

In summary, we developed a facile strategy for a highly sensitive and reproducible SERS substrate based on a hybrid nanostructure. A simple repeated dewetting process coupled with an ALD method was used to fabricate hierarchically assembled PMDM hybrid nano-architectures, which consist of core Au NPs and small out-layered Au NPs isolated by an $\mathrm{Al}_{2} \mathrm{O}_{3}$ layer. FDTD simulation data reveal that the use of the hybrid nanostructures leads to a high density and more intense EM hot spots through the creation of nanogaps by a dielectric spacer. Consequently, the SERS measurements of hybrids nanostructures demonstrate a maximum EF of $1.3 \times 10^{8}$, a low detection limit of $10^{-11} \mathrm{M}$ R6G molecules, 
and an excellent reproducibility (RSDs less than 7.5\%). Thus, we believe that hybrid SERS substrates have the potential to be used in practical applications for the highly sensitive, rapid, and reproducible detection of biomolecules.

Supplementary Materials: The following supporting information can be downloaded at: https: / / www.mdpi.com/article/10.3390/nano12030401/s1. Figure S1: Histogram of Au NPs arrays on $\mathrm{Si} / \mathrm{SiO}_{2}$ substrate by the annealing of $10 \mathrm{~nm} \mathrm{Au}$ at $800{ }^{\circ} \mathrm{C}$ for $120 \mathrm{~s}$; Figure S2: Raman spectra of R6G molecules (10-6 M) measured at 30 different locations on PMDM hybrid nanostructures to test the SERS reproducibility; Table S1: Raman band assignments of R6G molecules; Table S2: Comparison of SERS performance of current work and previously reported plasmonic NP-based SERS substrates (references [45-53] are cited in Table S2).

Author Contributions: Conceptualization, P.P. and J.I.S.; methodology, P.P., K.H.S. and M.-K.S.; software, P.P.; validation, P.P. and J.I.S.; formal analysis, P.P., M.-K.S., K.H.S. and J.I.S.; investigation, P.P., M.-K.S. and K.H.S.; resources, P.P. and J.I.S.; data curation, P.P., Y.-W.L. and J.I.S.; writingoriginal draft preparation, P.P., Y.-W.L. and J.I.S.; writing-review and editing, P.P., Y.-W.L. and J.I.S.; visualization, P.P.; supervision, J.I.S.; funding acquisition, P.P. and J.I.S. All authors have read and agreed to the published version of the manuscript.

Funding: This research was supported by the National Research Foundation of Korea (NRF) grant funded by the Korean government (MSIT) (2019R1A2C1007883 and 2021R1F1A1060364). This result was also supported by "Regional Innovation Strategy (RIS)" through the National Research Foundation of Korea (NRF) funded by the Ministry of Education (MOE) (2021RIS-004).

Institutional Review Board Statement: Not applicable.

Informed Consent Statement: Not applicable.

Data Availability Statement: Data are contained within the article or Supplementary Material.

Conflicts of Interest: The authors declare no conflict of interest.

\section{References}

1. Sharma, B.; Frontiera, R.R.; Henry, A.I.; Ringe, E.; Van Duyne, R.P. SERS: Materials, applications, and the future. Mater. Today 2012, 15, 16-25. [CrossRef]

2. $\quad$ Li, Y.; Wang, Y.; Fu, C.; Wu, Y.; Cao, H.; Shi, W.; Jung, Y.M. A simple enzyme-free SERS sensor for the rapid and sensitive detection of hydrogen peroxide in food. Analyst 2020, 145, 607-612. [CrossRef] [PubMed]

3. Plou, J.; García, I.; Charconnet, M.; Astobiza, I.; García-Astrain, C.; Matricardi, C.; Mihi, A.; Carracedo, A.; Liz-Marzán, L.M. Multiplex SERS Detection of Metabolic Alterations in Tumor Extracellular Media. Adv. Funct. Mater. 2020, 30, 1910335. [CrossRef]

4. Pandey, P.; Shin, K.; Jang, A.R.; Seo, M.K.; Hong, W.K.; Sohn, J.I. Highly sensitive multiplex-detection of surface-enhanced Raman scattering via self-assembly arrays of porous AuAg nanoparticles with built-in nanogaps. J. Alloys Compd. 2021, 888, 161504. [CrossRef]

5. Yang, H.; Gun, X.; Pang, G.; Zheng, Z.; Li, C.; Yang, C.; Wang, M.; Xu, K. Femtosecond laser patterned superhydrophobic/hydrophobic SERS sensors for rapid positioning ultratrace detection. Opt. Express 2021, 29, 16904-16913. [CrossRef]

6. Mao, P.; Liu, C.; Favraud, G.; Chen, Q.; Han, M.; Fratalocchi, A.; Zhang, S. Broadband single molecule SERS detection designed by warped optical spaces. Nat. Commun. 2018, 9, 5428. [CrossRef]

7. Blackie, E.J.; Ru, E.C.L.; Etchegoin, P.G. Single-molecule surface-enhanced Raman spectroscopy of nonresonant molecules. J. Am. Chem. Soc. 2009, 131, 14466-14472. [CrossRef]

8. Zhang, Y.; Gu, Y.; He, J.; Thackray, B.D.; Ye, J. Ultrabright gap-enhanced Raman tags for high-speed bioimaging. Nat. Commun. 2019, 10, 3905. [CrossRef]

9. Kim, J.; Nam, S.H.; Lim, D.K.; Suh, Y.D. SERS-based particle tracking and molecular imaging in live cells: Toward the monitoring of intracellular dynamics. Nanoscale 2019, 11, 21724-21727. [CrossRef]

10. Zhu, Y.; Tang, H.; Wang, H.; Li, Y. In Situ SERS Monitoring of the Plasmon-Driven Catalytic Reaction by Using Single Ag@Au Nanowires as Substrates. Anal. Chem. 2021, 93, 11736-11744. [CrossRef]

11. He, J.; Song, G.; Wang, X.; Zhou, L.; Li, J. Multifunctional magnetic $\mathrm{Fe}_{3} \mathrm{O}_{4} / \mathrm{GO} / \mathrm{Ag}$ composite microspheres for SERS detection and catalytic degradation of methylene blue and ciprofloxacin. J. Alloys Compd. 2022, 893, 162226. [CrossRef]

12. Tian, L.; Su, M.; Yu, F.; Xu, Y.; Li, X.; Li, L.; Liu, H.; Tan, W. Liquid-state quantitative SERS analyzer on self-ordered metal liquid-like plasmonic arrays. Nat. Commun. 2018, 9, 3642. [CrossRef]

13. Lee, H.K.; Lee, Y.H.; Koh, C.S.L.; Phan-Quang, G.C.; Han, X.; Lay, C.L.; Sim, H.Y.F.; Kao, Y.-C.; An, Q.; Ling, X.Y. Designing surfaceenhanced Raman scattering (SERS) platforms beyond hotspot engineering: Emerging opportunities in analyte manipulations and hybrid materials. Chem. Soc. Rev. 2019, 48, 731-756. [CrossRef] 
14. Li, Z.; Jiang, S.; Huo, Y.; Ning, T.; Liu, A.; Zhang, C.; He, Y.; Wang, M.; Li, C.; Man, B. 3D silver nanoparticles with multilayer graphene oxide as a spacer for surface enhanced Raman spectroscopy analysis. Nanoscale 2018, 10, 5897-5905. [CrossRef]

15. Dai, Z.; Xiao, X.; Wu, W.; Zhang, Y.; Liao, L.; Guo, S.; Ying, J.-J.; Shan, C.-X.; Sun, M.; Jiang, C.-Z. Plasmon-driven reaction controlled by the number of graphene layers and localized surface plasmon distribution during optical excitation. Light Sci. Appl. 2015, 4, e342. [CrossRef]

16. Yin, Z.; Xu, K.; Jiang, S.; Luo, D.; Chen, R.; Xu, C.; Shum, P.; Liu, Y.J. Recent progress on two-dimensional layered materials for surface enhanced Raman spectroscopy and their applications. Mater. Today Phys. 2021, 18, 100378. [CrossRef]

17. Zhang, C.; Li, C.; Yu, J.; Jiang, S.; Xu, S.; Yang, C.; Liu, Y.J.; Gao, X.; Liu, A.; Man, B. SERS activated platform with three-dimensional hot spots and tunable nanometer gap. Sens. Actuators B Chem. 2018, 258, 163-171. [CrossRef]

18. Tian, F.; Bonnier, F.; Casey, A.; Shanahan, A.E.; Byrne, H.J. Surface enhanced Raman scattering with gold nanoparticles: Effect of particle shape. Anal. Methods 2014, 6, 9116-9123. [CrossRef]

19. Chang, Y.C.; Dvoynenko, M.M.; Ke, H.; Hsiao, H.H.; Wang, Y.L.; Wang, J.K. Double Resonance SERS Substrates: Ag Nanoparticles on Grating. J. Phys. Chem. C 2021, 125, 27267-27274. [CrossRef]

20. Markina, N.E.; Ustinov, S.N.; Zakharevich, A.M.; Markin, A.V. Copper nanoparticles for SERS-based determination of some cephalosporin antibiotics in spiked human urine. Anal. Chim. Acta 2020, 1138, 9-17. [CrossRef]

21. Quan, J.; Zhang, J.; Qi, X.; Li, J.; Wang, N.; Zhu, Y. A study on the correlation between the dewetting temperature of Ag film and SERS intensity. Sci. Rep. 2017, 7, 14771. [CrossRef]

22. Rycenga, M.; Xia, X.; Moran, C.H.; Zhou, F.; Qin, D.; Li, Z.Y.; Xia, Y. Generation of Hot Spots with Silver Nanocubes for Single-Molecule Detection by Surface-Enhanced Raman Scattering. Angew. Chem. Int. Ed. 2011, 50, 5473-5477. [CrossRef]

23. Dai, H.; Fu, P.; Li, Z.; Zhao, J.; Yu, X.; Sun, J.; Fang, H. Electricity mediated plasmonic tip engineering on single Ag nanowire for SERS. Opt. Express 2018, 26, 25031-25036. [CrossRef]

24. Li, S.; Pedano, M.L.; Chang, S.H.; Mirkin, C.A.; Schatz, G.C. Gap structure effects on surface-enhanced Raman scattering intensities for gold gapped rods. Nano Lett. 2010, 10, 1722-1727. [CrossRef]

25. Cheng, Y.W.; Wu, C.H.; Chen, W.T.; Liu, T.Y.; Jeng, R.J. Manipulated interparticle gaps of silver nanoparticles by dendronexfoliated reduced graphene oxide nanohybrids for SERS detection. Appl. Surf. Sci. 2019, 469, 887-895. [CrossRef]

26. Wang, X.; Zhu, X.; Shi, H.; Chen, Y.; Chen, Z.; Zeng, Y.; Duan, H. Three-dimensional-stacked gold nanoparticles with sub-5 nm gaps on vertically aligned $\mathrm{TiO}_{2}$ nanosheets for surface-enhanced Raman scattering detection down to $10 \mathrm{fM}$ scale. ACS Appl. Mater. Interfaces 2018, 10, 35607-35614. [CrossRef]

27. Xu, K.; Zhang, C.; Lu, T.H.; Wang, P.; Zhou, R.; Ji, R.; Hong, M. Hybrid metal-insulator-metal structures on Si nanowires array for surface enhanced Raman scattering. Opto-Electron. Eng. 2017, 44, 185-191.

28. Hu, J.; Yu, H.; Su, G.; Song, B.; Wang, J.; Wu, Z.; Zhan, P.; Liu, F.; Wu, W.; Wang, Z. Dual-Electromagnetic Field Enhancements through Suspended Metal/Dielectric/Metal Nanostructures and Plastic Phthalates Detection in Child Urine. Adv. Opt. Mater. 2020, 8, 1901305. [CrossRef]

29. Tatmyshevskiy, M.K.; Yakubovsky, D.I.; Kapitanova, O.O.; Solovey, V.R.; Vyshnevyy, A.A.; Ermolaev, G.A.; Klishin, Y.A.; Mironov, M.S.; Voronov, A.A.; Arsenin, A.V.; et al. Hybrid Metal-Dielectric-Metal Sandwiches for SERS Applications. Nanomaterials 2021, 11, 3205. [CrossRef] [PubMed]

30. Ma, L.; Wang, J.; Huang, H.; Zhang, Z.; Li, X.; Fan, Y. Simultaneous thermal stability and ultrahigh sensitivity of heterojunction SERS substrates. Nanomaterials 2019, 9, 830. [CrossRef] [PubMed]

31. Preston, A.S.; Hughes, R.A.; Dominique, N.L.; Camden, J.P.; Neretina, S. Stabilization of Plasmonic Silver Nanostructures with Ultrathin Oxide Coatings Formed Using Atomic Layer Deposition. J. Phys. Chem. C 2021, 125, 17212-17220. [CrossRef]

32. Yang, C.; Chen, Y.; Liu, D.; Chen, C.; Wang, J.; Fan, Y.; Huang, S.; Lei, W. Nanocavity-in-multiple nanogap plasmonic coupling effects from vertical sandwich-like $\mathrm{Au} @ \mathrm{Al}_{2} \mathrm{O}_{3} @$ Au arrays for surface-enhanced Raman scattering. ACS Appl. Mater. Interfaces 2018, 10, 8317-8323. [CrossRef]

33. Pandey, P.; Kunwar, S.; Shin, K.H.; Seo, M.K.; Yoon, J.; Hong, W.K.; Sohn, J.I. Plasmonic Core-Shell-Satellites with Abundant Electromagnetic Hotspots for Highly Sensitive and Reproducible SERS Detection. Int. J. Mol. Sci. 2021, 22, 12191. [CrossRef]

34. Dai, F.; Horrer, A.; Adam, P.M.; Fleischer, M. Accessing the hotspots of cavity plasmon modes in vertical metal-insulator-metal structures for surface enhanced Raman scattering. Adv. Opt. Mater. 2020, 8, 1901734. [CrossRef]

35. Li, M.-Y.; Yu, M.; Jiang, S.; Liu, S.; Liu, H.; Xu, H.; Su, D.; Zhang, G.; Chen, Y.; Wu, J. Controllable 3D plasmonic nanostructures for high-quantum-efficiency UV photodetectors based on 2D and 0D materials. Mater. Horiz. 2020, 7, 905-911. [CrossRef]

36. Liu, J.; Chu, L.; Yao, Z.; Mao, S.; Zhu, Z.; Lee, J.; Wang, J.; Belfiore, L.A.; Tang, J. Fabrication of Au network by low-degree solid state dewetting: Continuous plasmon resonance over visible to infrared region. Acta Mater. 2020, 188, 599-608. [CrossRef]

37. Johnson, P.B.; Christy, R.W. Optical constants of the noble metals. Phys. Rev. B 1972, 6, 4370. [CrossRef]

38. Shi, Y.; Wang, J.; Wang, C.; Zhai, T.-T.; Bao, W.-J.; Xu, J.-J.; Xia, X.-H.; Chen, H.-Y. Hot electron of Au nanorods activates the electrocatalysis of hydrogen evolution on $\mathrm{MoS}_{2}$ Nanosheets. J. Am. Chem. Soc. 2015, 137, 7365-7370. [CrossRef]

39. Alshehri, A.H.; Mistry, K.; Nguyen, V.H.; Ibrahim, K.H.; Muñoz-Rojas, D.; Yavuz, M.; Musselman, K.P. Quantum-Tunneling Metal-Insulator-Metal Diodes Made by Rapid Atmospheric Pressure Chemical Vapor Deposition. Adv. Funct. Mater. 2019, 29, 1805533. [CrossRef]

40. Shao, F.; Lu, Z.; Liu, C.; Han, H.-Y.; Chen, K.; Li, W.; He, Q.; Peng, H.; Chen, J. Hierarchical nanogaps within bioscaffold arrays as a high-performance SERS substrate for animal virus biosensing. ACS Appl. Mater. Interfaces 2014, 6, 6281-6289. [CrossRef] 
41. Xu, J.; Kvasnička, P.; Idso, M.; Jordan, R.W.; Gong, H.; Homola, J.; Yu, Q. Understanding the effects of dielectric medium, substrate, and depth on electric fields and SERS of quasi-3D plasmonic nanostructures. Opt. Express 2011, 19, 20493-20505. [CrossRef]

42. Yuan, K.; Zheng, J.; Yang, D.; Sánchez, B.J.; Liu, X.; Guo, X.; Liu, C.; Dina, N.E.; Jian, J.; Bao, Z.; et al. Self-assembly of Au@ Ag nanoparticles on mussel shell to form large-scale 3D supercrystals as natural SERS substrates for the detection of pathogenic bacteria. ACS Omega 2018, 3, 2855-2864. [CrossRef]

43. Lee, T.; Jung, D.; Wi, J.S.; Lim, H.; Lee, J.J. Surfactant-free galvanic replacement for synthesis of raspberry-like silver nanostructure pattern with multiple hot-spots as sensitive and reproducible SERS substrates. Appl. Surf. Sci. 2020, 505, 144548. [CrossRef]

44. Zhao, X.; Liu, C.; Yu, J.; Li, Z.; Liu, L.; Li, C.; Xu, S.; Li, W.; Man, B.; Zhang, C. Hydrophobic multiscale cavities for high-performance and self-cleaning surface-enhanced Raman spectroscopy (SERS) sensing. Nanophotonics 2020, 9, 4761-4773. [CrossRef]

45. Zhong, F.; Wu, Z.; Guo, J.; Jia, D. Porous silicon photonic crystals coated with Ag nanoparticles as efficient substrates for detecting trace explosives using SERS. Nanomaterials 2018, 8, 872. [CrossRef]

46. Purwidyantri, A.; Hsu, C.H.; Yang, C.M.; Prabowo, B.A.; Tian, Y.C.; Lai, C.S. Plasmonic nanomaterial structuring for SERS enhancement. RSC Adv. 2019, 9, 4982-4992. [CrossRef]

47. Waiwijit, U.; Chananonnawathorn, C.; Eimchai, P.; Bora, T.; Hornyak, G.L.; Nuntawong, N. Fabrication of Au-Ag nanorod SERS substrates by co-sputtering technique and dealloying with selective chemical etching. Appl. Surf. Sci. 2020, 530, 147171. [CrossRef]

48. Xue, Y.; Paschalidou, E.M.; Rizzi, P.; Battezzati, L.; Denis, P.; Fecht, H.J. Nanoporous gold thin films synthesised via de-alloying of Au-based nanoglass for highly active SERS substrates. Philos. Mag. 2018, 98, 2769-2781. [CrossRef]

49. Zhu, J.; Wu, N.; Zhang, F.; Li, X.; Li, J.; Zhao, J. SERS detection of 4-Aminobenzenethiol based on triangular Au-AuAg hierarchicalmultishell nanostructure. Spectrochim. Acta-Part A Mol. Biomol. Spectrosc. 2018, 204, 754-762. [CrossRef] [PubMed]

50. Zhou, Y.; Liang, P.; Zhang, D.; Tang, L.; Dong, Q.; Jin, S.; Ni, D.; Yu, Z.; Ye, J. A facile seed growth method to prepare stable Ag@ $\mathrm{ZrO}_{2}$ core-shell SERS substrate with high stability in extreme environments. Spectrochim. Acta Part A Mol. Biomol. Spectrosc. 2020, 228, 117676. [CrossRef]

51. Wang, J.; Li, J.; Zeng, C.; Qu, Q.; Wang, M.; Qi, W.; Su, R.; He, Z. Sandwich-like sensor for the highly specific and reproducible detection of Rhodamine 6G on a surface-enhanced Raman scattering platform. ACS Appl. Mater. Interfaces 2020, 12, $4699-4706$. [CrossRef]

52. Fathima, H.; Mohandas, N.; Varghese, B.S.; Anupkumar, P.; Swathi, R.S.; Thomas, K.G. Core-Shell Plasmonic Nanostructures on Au Films as SERS Substrates: Thickness of Film and Quality Factor of Nanoparticle Matter. J. Phys. Chem. C 2021, 125, 16024-16032. [CrossRef]

53. Wang, Y.; Jin, A.; Quan, B.; Liu, Z.; Li, Y.; Xia, X.; Li, W.; Yang, H.; Gu, C.; Li, J. Large-scale Ag-nanoparticles/Al ${ }_{2} \mathrm{O}_{3} / \mathrm{Au}^{-}$ nanograting hybrid nanostructure for surface-enhanced Raman scattering. Microelectron. Eng. 2017, 172, 1-7. [CrossRef] 